\title{
Eficiência de sistemas evaporativos e dos níveis de energia na ração no desempenho de frangos de corte em crescimento ${ }^{1}$
}

\section{Efficiency of evaporative systems and ration energy levels on the performance of growing meat chicken}

\author{
Orlando Rus Barbosa ${ }^{2 *}$; Mariusa de Lima ${ }^{3}$; Élcio Silvério Klosowski; \\ Meiby Carneiro de Paula Leite ${ }^{5}$, Deise Dalazen Castagnara ${ }^{6}$; Caroline Capossi $^{7}$
}

\section{Resumo}

Foram utilizados dois galpões aviários, sendo o galpão 1 (SRAE) equipado com um sistema de resfriamento adiabático evaporativo e o galpão 2 (SRAE+SETV) equipado com um sistema de resfriamento adiabático evaporativo associado a um sistema evaporativo de tijolos vazados, instalado frontal e lateralmente a este galpão. Foram avaliadas a temperatura e a umidade relativa do ar por meio de equipamentos automáticos (datalogger), juntamente com o Índice Térmico Ambiental de Produtividade para frangos de corte (IAPfc). Utilizou-se 960 aves, machos, da linhagem Cobb, sendo as rações experimentais isoprotéicas, com exceção dos níveis energéticos, que foram de 3100, 3200, 3300 e $3400 \mathrm{kcal}$. A utilização do sistema de resfriamento adiabático evaporativo SRAE foi mais eficiente quando associado ao sistema evaporativo de tijolos vazados SETV. O SRAE+SETV proporcionou um ambiente mais confortável e homogêneo mostrando efeito sobre os parâmetros produtivos, favorecendo a conversão alimentar. Mesmo os galpões apresentando ambientes moderadamente confortáveis, segundo os valores do IAPfc obtidos, o SRAE+SETV mostrou melhor equilíbrio nas condições ambientais entre as sessões. Os níveis de energia influenciaram apenas a deposição da gordura abdominal.

Palavras-chave: Conforto térmico, desempenho, órgãos, resfriamento adiabático evaporativo

\begin{abstract}
Two aviary sheds were used, the shed 1 (AECS) equipped with an adiabatic evaporative cooling system and the shed 2 (AECS + ESPB) equipped with an adiabatic evaporative cooling system together with an evaporative system of perforated bricks in the front and side of the shed. The temperature and the relative humidity of the air were assessed with automated devices (datalogger), together with the Environmental Thermal Index of Productivity for meat chicken (ETIPmc). Nine hundred and sixty male chickens from the Cobb strain were used, fed with isoproteic diets, except for the energy levels, which varied from 3,100 to 3,400 kcal. The use of the AECS was more efficient when associated to the ESPB. The AECS + ESPB provided a more comfortable and homogeneous environment, reflected on the productive parameters and favoring food conversion. Although the sheds exhibited moderately comfortable environments, according to the ETIPmc obtained, the AECS + ESPB showed a better balance of the environmental conditions between the sessions. The energy levels did not influence the variables analyzed, with the exception of the deposition of abdominal fat.
\end{abstract}

Key words: Evaporative adiabatic cooling, organs thermal comfort, performance

1 Programa de Pós-graduação em Zootecnia, Universidade Estadual de Maringá, UEM, Av. Colombo, 5790, 87020-900, Maringá, PR.

2 Prof. do Dept ${ }^{\mathrm{o}}$ de Zootecnia, UEM, Maringá, PR. E-mail: orbarbosa@uem.br

3 Pós-Graduanda do Programa de Pós-graduação em Zootecnia, UEM, Maringá, PR. E-mail: mariusalima@hotmail.com

4 Prof. do Dept ${ }^{0}$ de Zootecnia, Universidade Estadual do Oeste do Paraná, UNIOESTE, Marechal Cândido Rondon, PR. E-mail: elciok1@yahoo.com.br

5 Prof $^{\mathrm{a}} \mathrm{Dr}^{\mathrm{a}}$ do Centro de Ciências Agrárias Ambientais e Biológicas, Universidade Federal do Recôncavo Baiano, UFRB, Cruz das Almas, Bahia, BA. E-mail: ccaab@ufrb.edu.br

6 Discente do Curso de Agronomia, UNIOESTE, Marechal Cândido Rondon, PR. E-mail: deisecastagnara@hotmail.com

7 Discente do Curso de Zootecnia, UNIOESTE, Marechal Cândido Rondon, PR. E-mail: carol.capossi@hotmail.com

Autor para correspondência 


\section{Introdução}

A interação animal e ambiente deve ser considerada quando se busca maior eficiência na exploração pecuária, pois diferentes respostas do animal às peculiaridades de cada região são determinantes no sucesso da atividade. Assim, a correta identificação dos fatores que influem na vida produtiva do animal, como o estresse imposto pelas flutuações estacionais do meio ambiente, permite ajustes nas práticas de manejo dos sistemas de produção, possibilitando oferecer sustentabilidade e viabilidade econômica. Dessa forma, o conhecimento das variáveis climáticas, sua interação com os animais e as respostas comportamentais, fisiológicas e produtivas são preponderantes na adequação do sistema de produção aos objetivos da atividade (NEIVA et al., 2004).

A temperatura ambiente modifica a retenção de energia, proteína e gordura no corpo do animal e provoca diversas mudanças adaptativas fisiológicas, entre elas a modificação do tamanho dos órgãos, redução do consumo de ração acompanhada de piora no ganho de peso e na conversão alimentar (BAZIZ; GERAERT; GUILLAUMIN, 1996; BALDUIN et. al., 1980 citado por OLIVEIRA et al., 2006).

Além da temperatura ambiente, o nível energético das rações também influencia o desempenho e a composição da carcaça de frangos de corte, daí a importância de se tratarem conjuntamente os fatores climáticos e dietéticos e climáticos (LANA et al., 2000).

Conforme Welker et al. (2008), em países de clima tropical e subtropical, a exemplo do Brasil, faz-se necessário o emprego de métodos capazes de manter o equilíbrio térmico entre o animal e o meio. Deste modo objetivou-se, com o presente estudo, avaliar a eficiência de sistemas evaporativos e dos níveis de energia na ração no desempenho de frangos de corte em crescimento.

\section{Material e Métodos}

O trabalho foi conduzido em uma propriedade comercial para produção de frangos de corte, localizada no distrito de Iguiporã, no município de Marechal Cândido Rondon na região Oeste do Paraná (altitude média de $420 \mathrm{~m}$, latitude

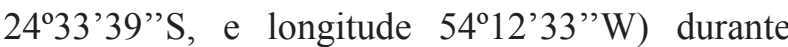
o período de verão. O clima local, de acordo com a Classificação Climática de Köpen-Geiger, é do tipo Cfa, subtropical com chuvas bem distribuídas durante o ano e verões quentes. As temperaturas médias do trimestre mais frio variam entre $17 \mathrm{e}$ $18^{\circ} \mathrm{C}$, do trimestre mais quente entre 28 e $29^{\circ} \mathrm{C}$ e a anual entre 22 e $23^{\circ} \mathrm{C}$. Os totais anuais médios normais de precipitação pluvial para a região variam entre 1600 e $1800 \mathrm{~mm}$, com o trimestre mais chuvoso apresentando totais variando entre 400 e $500 \mathrm{~mm}$ (CAVIGLIONE et al., 2000).

Foram utilizados dois galpões semelhantes de $130 \mathrm{~m}$ de comprimento por 14 metros de largura e pé direito de $2,80 \mathrm{~m}$, ambos com idênticas características, orientados no sentido norte-sul e espaçados $100 \mathrm{~m}$ um do outro.

A cobertura dos galpões era de telha de cerâmica americana, com inclinação do telhado de $48 \%$ e beirais de $1,0 \mathrm{~m}$, sendo as muretas protetoras em alvenaria de $0,40 \mathrm{~m}$ de altura por $0,10 \mathrm{~m}$ de espessura, a partir das quais os galpões foram fechados com tela de arame de malha $20 \mathrm{~mm}$ e equipados com cortina de propex plastificada.

O galpão 1 (SRAE) foi servido com sistema de resfriamento adiabático evaporativo, com sistema de nebulização composto de 30 linhas no sentido transversal ao galpão, as quais continham 8 bicos eqüidistantes a $1,75 \mathrm{~m}, 13$ linhas contendo 7 bicos eqüidistantes a $2 \mathrm{~m}$, e uma linha de nebulizadores em forma de U na parte anterior no galpão, contendo 6 bicos eqüidistantes a $2,34 \mathrm{~m}$, totalizando 337 bicos aspersores em cada galpão. A ventilação negativa foi realizada por 8 exaustores com velocidade do ar de $2,7 \mathrm{~m} . \mathrm{s}^{-1}$ posicionados na parte posterior do galpão. O galpão 2 (SRAE +SETV) foi constituído pelo mesmo sistema de resfriamento adiabático evaporativo, presente no galpão 1 , diferenciandose deste pela presença de um sistema composto de placas de tijolos vazados (SETV) instaladas frontal e lateralmente no oitão norte conforme Figura 1. 
Figura 1.Vista frontal e posterior do galpão1 (SRAE), vista frontal e lateral do galpão 2 (SRAE+SETV).

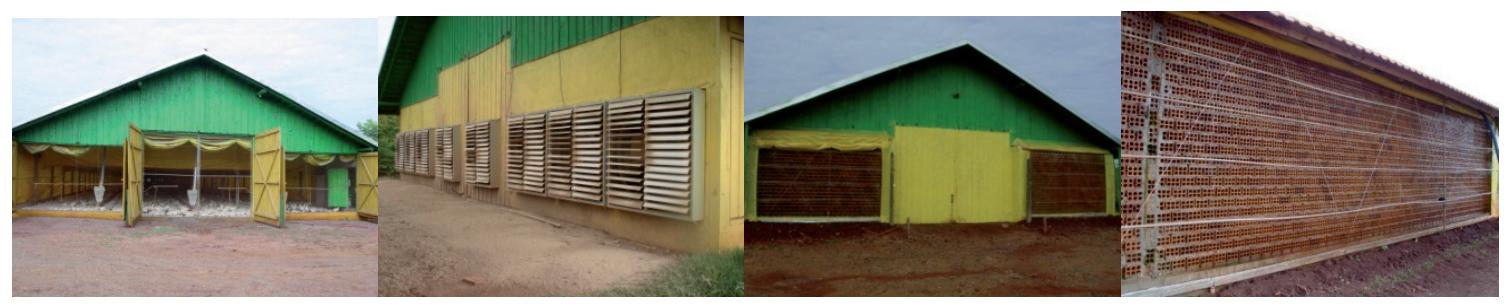

Fonte: Elaboração dos autores.

Este sistema era constituído de 4 placas de tijolos vazados, sendo que duas foram instaladas nas laterais do galpão para cada entrada de ar (uma de cada lado), medindo $2,45 \mathrm{~m}$ de altura e $13 \mathrm{~m}$ de largura e duas na parte frontal, medindo 2,45 $\mathrm{m}$ de altura e 4,36 $\mathrm{m}$ de largura, com espessura de $0,40 \mathrm{~m}$. Em cada uma das placas laterais foram instaladas 4 linhas de nebulizadores equidistantes a $0,49 \mathrm{~m}$ contendo 10 bicos aspersores equidistantes a 1,3 m. As placas frontais consistiam de 4 linhas de nebulização equidistantes a $0,49 \mathrm{~m}$, sendo que a $1^{\mathrm{a}}$ e a $3^{\mathrm{a}}$ linhas continham 5 bicos equidistantes a $0,87 \mathrm{~m}$ e a $2^{\mathrm{a}}$ e $4^{\mathrm{a}}$ linhas foram compostas de 4 bicos equidistantes a $1,09 \mathrm{~m}$, perfazendo um total de 18 bicos aspersores.

Os valores de temperatura e umidade relativa do ar foram obtidas por meio de 6 equipamentos automáticos (datalogger), da marca AKSO, modelo AK 270, com escala de temperatura de $-40 \mathrm{a}+85^{\circ} \mathrm{C}$, escala de umidade de 0 a $100 \%$ e com capacidade de memória para armazenamento de 16000 registros.

Dentro de cada galpão foram utilizados 3 dataloggers, sendo um instalado a uma distância de 12,50 metros da parede norte do galpão, o segundo na parte central do galpão, distante 52,5 metros do primeiro datalogger e o terceiro disposto a 52,50 metros do segundo equipamento e distante 12,50 metros da parede sul da instalação. A altura em que foram instalados variou conforme a idade das aves. Os dados do ambiente externo de temperatura e umidade relativa do ar foram coletados na Estação

A velocidade do vento no interior dos galpões foi obtida por meio de um anemômetro da marca Instrutherm, modelo AD-155, com sensor de ventoinha, escala de 0,8 a $30,0 \mathrm{~m} \cdot \mathrm{s}^{-1}$ e resolução de $91 \mathrm{~m} \cdot \mathrm{s}^{-1}$.

A partir de dados climáticos coletados durante as 24 horas do dia, e obtidos a cada 15 minutos do $21^{\circ}$ ao $42^{\circ}$ dia de vida das aves, obteve-se os valores que caracterizaram o ambiente térmico por meio do Índice Térmico Ambiental de Produtividade para frangos de corte (IAPfc), segundo Medeiros et al. (2005).

A expressão é dada por:

$$
\begin{gathered}
\text { IAPfc }=45,6026-2,31072 \mathrm{t}-0,368331 \mathrm{u} \\
+9,70922 \mathrm{v}+0,0549243 \mathrm{t}^{2}+0,0012183 \mathrm{u}^{2} \\
+0,66329 \mathrm{v}^{2}+0,012897 \mathrm{tu}-0,300928 \mathrm{tv}- \\
0,0595245 \mathrm{uv}
\end{gathered}
$$

em que:

$\mathrm{t}=$ temperatura do ar, ${ }^{\circ} \mathrm{C}$;

$\mathrm{u}=$ umidade relativa do ar, $\%$;

$\mathrm{v}=$ velocidade do ar, $\mathrm{m} \cdot \mathrm{s}^{-1}$

O delineamento experimental foi de blocos inteiramente casualizado, num modelo fatorial $2 \times 4$ (galpões x níveis de energia) com 4 repetições e 30 aves da linhagem Cobb, por unidade experimental, perfazendo um total de 960 aves. Aplicou-se em um galpão (SRAE) o sistema de resfriamento adiabático evaporativo e no outro galpão (SRAE + SETV) ou seja, o sistema SRAE combinado com o sistema evaporativo de tijolos vazados (SETV). Cada galpão foi dividido em quatro sessões iguais de $26,25 \mathrm{~m}$, sendo cada sessão constituída por quatro boxes de 1,5 $\mathrm{m}$ de largura por 2,00 $\mathrm{m}$ de comprimento e 0,75 $\mathrm{m}$ de altura cada um, confeccionados com madeira e tela de arame, num total de 16 boxes contendo cada um 30 aves (Figura 5). Os níveis de energia 
(tratamentos) foram distribuídos aleatoriamente dentro das sessões, de forma que cada box representava o tratamento a ser testado. Em cada box foi disponibilizado comedouro tubular manual com capacidade de $20 \mathrm{~kg}$, o qual permaneceu suspenso em um cavalete, de onde era possível controlar a altura conforme a necessidade das aves e 10 bicos bebedouros do tipo nipple com vazão de
$110 \mathrm{~mL}$ por minuto, com altura regulada conforme o crescimento e a necessidade das aves.

$\mathrm{Na}$ fase experimental (22 a 42 dias) as exigências nutricionais foram atendidas para todos os nutrientes segundo Rostagno et al. (2005), com exceção dos níveis energéticos. As rações experimentais foram formuladas à base de milho, farelo de soja e soja integral tostada (Tabela 1).

Tabela 1. Composição percentual e calculada das rações experimentais.

\begin{tabular}{|c|c|c|c|c|}
\hline \multirow[t]{2}{*}{ Ingrediente } & \multicolumn{4}{|c|}{ Nível de Energia Metabolizável (kcal/kg) } \\
\hline & 3100 & 3200 & 3300 & 3400 \\
\hline Milho & 65,487 & 62,795 & 60,493 & 58,191 \\
\hline Farelo de soja & 22,100 & 14,400 & 12,200 & 10,900 \\
\hline Soja integral & 5,300 & 15,100 & 18,000 & 20,000 \\
\hline Óleo Soja & 0,800 & 1,000 & 2,400 & 3,900 \\
\hline Calcáreo & 0,500 & 0,300 & 0,300 & 0,300 \\
\hline Farinha de carne & 4,300 & 4,900 & 5,100 & 5,200 \\
\hline Sal comum & 0,351 & 0,353 & 0,352 & 0,356 \\
\hline DL-Metionina (99\%) & 0,265 & 0,267 & 0,270 & 0,274 \\
\hline Bicarbonato de sódio & 0,064 & 0,058 & 0,058 & 0,055 \\
\hline L-Lisina $\mathrm{HCl}(99 \%)$ & 0,269 & 0,271 & 0,270 & 0,267 \\
\hline L-Treonina $(98,5 \%)$ & 0,099 & 0,097 & 0,097 & 0,098 \\
\hline Cloreto de colina $(60 \%)$ & 0,006 & 0,006 & 0,006 & 0,006 \\
\hline Galliacid $^{1}$ & 0,060 & 0,060 & 0,060 & 0,060 \\
\hline Premix vitamínico e mineral ${ }^{2}$ & 0,400 & 0,400 & 0,400 & 0,400 \\
\hline Total & 100,001 & 100,007 & 100,006 & 100,007 \\
\hline \multicolumn{5}{|l|}{ Composição calculada } \\
\hline Energia metabolizável (kcal/kg) & 3100 & 3200 & 3300 & 3400 \\
\hline Proteína bruta $(\%)$ & 20,210 & 20,290 & 20,280 & 20,230 \\
\hline Gordura bruta (\%) & 5,170 & 7,270 & 9,160 & 11,010 \\
\hline Cálcio (\%) & 0,840 & 0,840 & 0,840 & 0,840 \\
\hline Fósforo disponível (\%) & 0,450 & 0,470 & 0,480 & 0,480 \\
\hline Sódio & 0,200 & 0,200 & 0,200 & 0,200 \\
\hline Cloro (\%) & 0,360 & 0,360 & 0,360 & 0,360 \\
\hline Potássio (\%) & 0,760 & 0,760 & 0,760 & 0,760 \\
\hline Balanço eletrolítico $(\mathrm{mEq} / \mathrm{kg})$ & 249,410 & 249,410 & 249,410 & 249,410 \\
\hline
\end{tabular}

${ }^{1}$ Aditivo acidificante de ácidos orgânicos microencapsulados indicados para aves. Níveis de garantia por kg do produto (mg): ácido fumárico $=250.000$, propionato de cálcio $=40.000$, formiato de cálcio $=80.000$, sorbato de potássio $=20.000$.

${ }^{2}$ Níveis de garantia do produto: manganês $=18.719 \mathrm{mg}$, zinco $=37.500 \mathrm{mg}$, ferro $=11.250 \mathrm{mg}$, cobre $=1.997 \mathrm{mg}$, iodo $=187.50$ $\mathrm{mg}$, selênio $=75 \mathrm{mg}$, vitamina $\mathrm{A}=2.000 .000 \mathrm{UI}$, vitamina D3 $=475.000 \mathrm{UI}$, vitamina $\mathrm{E}=5.000 \mathrm{mg}$, vitamina K3 $450 \mathrm{mg}$, vitamina $\mathrm{B} 1=450 \mathrm{mg}$, vitamina B2 $=1.375 \mathrm{mg}$, vitamina B6 = $650 \mathrm{mg}$, vitamina B12 = $3750 \mathrm{mcg}$, ácido fólico $=3.750 \mathrm{mg}$, ácido pantotênico $=3.250 \mathrm{mg}$, niacina $=8.750 \mathrm{mg}$, biotina $=12.500 \mathrm{mcg}$, colina $=73,575 \mathrm{mg}, \mathrm{BHT}=31.250 \mathrm{mg}$, maduramicina $=1.375$ $\mathrm{mg}$, enramicina $=2.500 \mathrm{mg}$, fitase $=25.00 \mathrm{mg}$.

Fonte: Elaboração dos autores. 
Os parâmetros produtivos avaliados foram: peso aos 42 dias de idade (P42), consumo de ração corrigido (CRC), ganho de peso (GP), e conversão alimentar (CA), peso da ave viva (PAV), peso da ave eviscerada (PAE), peso da gordura abdominal (PG), peso do coração (PC) e peso do fígado (PF).

As análises estatísticas foram realizadas utilizando o procedimento GLM do SAS (2008), e as médias foram comparadas utilizando o teste de Tukey a 5\% de significância.

\section{Resultados e Discussão}

Os valores médios de temperatura e umidade relativa do ar encontrados nos diferentes galpões estão apresentados na Tabela 2.

Tabela 2. Médias estimadas da temperatura $\left({ }^{\circ} \mathrm{C}\right)$ e umidade relativa do ar $(\%)$ obtidas nos diferentes galpões no período de 22 a 42 dias.

\begin{tabular}{lcccc}
\hline & \multicolumn{4}{c}{ Períodos } \\
\cline { 2 - 5 } Galpão & $4^{\mathrm{a}}$ semana & $5^{\text {a }}$ semana & $6^{\text {a }}$ semana & Média \\
& $(22-28$ dias $)$ & $(23-35$ dias $)$ & $(36-42$ dias $)$ & $(22-42$ dias $)$ \\
\hline SRAE & $27,1^{\circ} \mathrm{C} / 78,3 \%$ & $25,2^{\circ} \mathrm{C} / 87,7 \%$ & $26,9^{\circ} \mathrm{C} / 78,7 \%$ & $26,4^{\circ} \mathrm{C} / 81,6 \%$ \\
SRAE+SETV & $25,9^{\circ} \mathrm{C} / 83,2 \%$ & $24,5^{\circ} \mathrm{C} / 84,7 \%$ & $26,4^{\circ} \mathrm{C} / 76,9 \%$ & $25,6^{\circ} \mathrm{C} / 81,6 \%$ \\
\hline
\end{tabular}

Fonte: Elaboração dos autores.

Os valores contrastam com os encontrados por Lana et. al. (2000) que afirmam como sendo ideais as temperaturas 32,29 e $23^{\circ} \mathrm{C}$ para este mesmo período. Segundo esses autores, a temperatura ambiente é o fator físico que mais afeta o desempenho de frangos de corte, pois influencia o consumo de ração, o ganho de peso e a conversão alimentar. Fora da zona de termoneutralidade, frangos de corte apresentam alterações comportamentais diferentes, em razão da necessidade desses animais de reduzir a produção de calor. No entanto, Moura (2001) afirma que a temperatura crítica superior passa de $35^{\circ} \mathrm{C}$ na terceira semana para $24^{\circ} \mathrm{C}$ na quarta semana, chegando a $21^{\circ} \mathrm{C}$ na sexta semana de vida.

As condições ambientais encontradas neste experimento podem ter ocasionado desconforto às aves, pois, segundo Rodrigues (1998), quando o ar está seco, a perda de calor por via latente é um processo bastante eficiente de dissipação de calor pela ave, porém, quando a umidade relativa e a temperatura do ar são altas, a ave não pode ofegar com rapidez suficiente para remover todo o calor que precisa dissipar, sendo, pois, a umidade relativa associada a altas temperaturas, fator limitante a produtividade das aves. Para temperatura de $24^{\circ} \mathrm{C}$ e umidade relativa de $40 \%$, o frango pode dissipar $50 \%$ de seu calor corporal por via latente, enquanto que para a mesma temperatura e umidade relativa de $85 \%$ (ar úmido), somente $22 \%$ do calor total consegue ser eliminado por via latente.

Baêta e Souza (1997) e Tinôco (2001) consideram o ambiente confortável para frangos de corte adultos, aquele com temperaturas entre 18 e $28^{\circ} \mathrm{C}$ e umidade relativa entre 50 e 70\%. Já Medeiros et al. (2005) analisando o índice térmico ambiental para a produção de frangos de corte, concluíram que a umidade relativa de $90 \%$ conduziu aos melhores resultados de produtividade para os animais, quando combinada com baixas temperaturas, ao passo que umidades relativas de $20 \%$ conduziram aos melhores resultados quando combinadas com altas temperaturas, na ausência de ventilação.

Os valores médios de temperatura do ar e umidade relativa do ar encontrados nas sessões de ambos os galpões durante todo o período estão apresentados na Tabela 3 . 
Estes resultados nos permitem afirmar que mesmo os dois galpões apresentando em média, ambiente moderadamente confortável, segundo os valores dos índices obtidos, o SRAE+SETV mostrou melhor equilíbrio nas condições ambientais entre as sessões.
As médias de consumo de ração corrigido (CRC), ganho de peso (GP), peso das aves aos 42dias (P42) e conversão alimentar (CA) $(\mathrm{kg})$ em função do galpão e dos níveis de EM estão presentes na Tabela 4.

Tabela 3. Médias estimadas de temperatura do $\operatorname{ar}\left({ }^{\circ} \mathrm{C}\right)$ e umidade relativa do ar (\%) e índice térmico ambiental de produtividade para frangos de corte (IAPfc) encontrados nas sessões de ambos os galpões durante todo o período.

\begin{tabular}{lccccc} 
& \multicolumn{5}{c}{ Sessão } \\
\cline { 2 - 6 } Galpão & 1 & 2 & 3 & 4 & Média \\
\hline SRAE & $25,8^{\circ} \mathrm{C} / 82,8 \%$ & $26,5^{\circ} \mathrm{C} / 79,7 \%$ & $26,5^{\circ} \mathrm{C} / 79,7 \%$ & $26,7^{\circ} \mathrm{C} / 84,8 \%$ & $26,4^{\circ} \mathrm{C} / 81,6 \%$ \\
IAPfc & 25 & 26 & 26 & 26 & 26 \\
SRAE+SETV & $25,3^{\circ} \mathrm{C} / 91,7 \%$ & $25,5^{\circ} \mathrm{C} / 77,2 \%$ & $25,5^{\circ} \mathrm{C} / 77,2 \%$ & $26,0^{\circ} \mathrm{C} / 81,0 \%$ & $25,6^{\circ} \mathrm{C} / 81,6 \%$ \\
IAPfc & 25 & 25 & 25 & 25 & 25 \\
\hline
\end{tabular}

Fonte: Elaboração dos autores.

Tabela 4. Médias estimadas e erros-padrão de consumo de ração corrigido (CRC) (kg), ganho de peso (GP) (kg), peso aos 42 dias (P42) (kg) e conversão alimentar (CA) em função do galpão e dos níveis de energia (kcal/kg).

\begin{tabular}{llccccc}
\hline \multicolumn{7}{c}{ Níveis de EM $(\mathrm{kcal} / \mathrm{kg})$} \\
\hline Variável & \multicolumn{1}{c}{ Galpão } & 3100 & 3200 & 3300 & 3400 & Média \\
\hline CRC & SRAE & $3,63 \pm 0,11$ & $3,73 \pm 0,07$ & $3,54 \pm 0,10$ & $3,57 \pm 0,08$ & $3,62 \pm 0,09 \mathrm{~A}$ \\
& SRAE+SETV & $3,35 \pm 0,07$ & $3,36 \pm 0,02$ & $3,34 \pm 0,05$ & $3,35 \pm 0,04$ & $3,35 \pm 0,43 \mathrm{~B}$ \\
\hline \multirow{2}{*}{ GP } & SRAE & $1,63 \pm 0,20$ & $1,80 \pm 0,13$ & $1,70 \pm 0,24$ & $1,81 \pm 0,24$ & $1,74 \pm 0,24 \mathrm{~A}$ \\
& SRAE+SETV & $1,74 \pm 0,70$ & $1,72 \pm 0,09$ & $1,75 \pm 0,07$ & $1,77 \pm 0,12$ & $1,74 \pm 0,24 \mathrm{~A}$ \\
\hline \multirow{2}{*}{ P42 } & SRAE & $2,64 \pm 0,22$ & $2,81 \pm 0,12$ & $2,71 \pm 0,23$ & $2,83 \pm 0,24$ & $2,75 \pm 0,20 \mathrm{~A}$ \\
& SRAE+SETV & $2,75 \pm 0,08$ & $2,71 \pm 0,09$ & $2,77 \pm 0,06$ & $2,78 \pm 0,12$ & $2,75 \pm 0,09 \mathrm{~A}$ \\
\hline CA & SRAE & $2,27 \pm 0,32$ & $2,07 \pm 0,17$ & $2,12 \pm 0,39$ & $2,00 \pm 0,27$ & $2,11 \pm 0,28 \mathrm{~A}$ \\
& SRAE+SETV & $1,92 \pm 0,09$ & $1,95 \pm 0,10$ & $1,92 \pm 0,09$ & $1,90 \pm 0,14$ & $1,92 \pm 0,10 \mathrm{~B}$ \\
\hline
\end{tabular}

Médias seguidas da mesma letra maiúscula não diferem entre si pelo teste $\mathrm{F}$ a $5 \%$.

Fonte: Elaboração dos autores.

O consumo de ração foi maior para as aves do SRAE, porém, acompanhado de piores valores de GP, P42 e CA. Estes resultados corroboram com os encontrados por Dale e Fuller (1980) que, utilizando a técnica do consumo pareado, observaram que, mesmo igualando o consumo, as aves submetidas ao estresse por calor não tiveram a mesma taxa de crescimento que as aves em ambiente termoneutro e que há uma redução na eficiência alimentar. A mesma ideia foi reforçada por Geraert, Padilha e Guillaumin (1996) e Baziz, Geraert e Guillaumin (1996) que relataram que quando mantidos em estresse por calor, os frangos de corte reduzem seu crescimento em maior proporção que o consumo de ração, o que resulta em pior índice de conversão alimentar.

Por outro lado, estes resultados contrastam com os encontrados por Bellay e Theeter (1993) que 
afirmam que em consequência do estresse por calor, a temperatura corporal da ave sobe e logo aparecem os sintomas negativos. Quando expostas a este tipo de estresse todas as aves respondem através da diminuição da ingestão de alimentos. A redução de consumo alimentar diminui os substratos metabólicos ou combustíveis disponíveis para o metabolismo, dessa forma, há redução da produção de calor.

As médias estimadas da conversão alimentar (CA) em função das sessões no interior do galpão, estão apresentadas na Tabela 5.

Tabela 5. Médias estimadas e erros-padrão da conversão alimentar (CA) em função das sessões no interior do galpão.

\begin{tabular}{lccccc}
\hline Galpão & \multicolumn{5}{c}{ Sessão } \\
\cline { 2 - 5 } & 1 & 2 & 3 & 4 & Médias \\
\hline SRAE & $1,87 \pm 0,13 \mathrm{Bb}$ & $1,95 \pm 0,10 \mathrm{Ab}$ & $2,25 \pm 0,30 \mathrm{Ba}$ & $2,35 \pm 0,25 \mathrm{Aa}$ & $2,11 \pm 0,59 \mathrm{~A}$ \\
SRAE+SETV & $1,92 \pm 0,10 \mathrm{Aa}$ & $1,92 \pm 0,10 \mathrm{Ab}$ & $1,90 \pm 0,14 \mathrm{Ab}$ & $1,95 \pm 0,10 \mathrm{Ab}$ & $1,92 \pm 0,11 \mathrm{~B}$ \\
\hline
\end{tabular}

Médias seguidas da mesma letra maiúscula nas linhas e minúsculas nas colunas não diferem entre si pelo teste de Tukey a $5 \%$. Fonte: Elaboração dos autores.

No galpão 1, a sessão 4 (Figura 2), apresentou maiores valores de conversão alimentar, fato este que pode estar relacionado à associação dos maiores valores de temperatura (média de $27,5^{\circ} \mathrm{C}$ ) e umidade $(79,7 \%)$ encontrada nesse local, não existindo diferenças nas demais sessões $(\mathrm{P}>0,05)$. Para o galpão 2, a CA não apresentou diferença $(\mathrm{P}>0,05)$ entre as sessões, mostrando o equilíbrio nas condições ambientais promovidas pelo sistema SETV.

Figura 2. Croqui do galpão e distribuição dos boxes com os diferentes níveis de energia (tratamentos) no interior dos galpões.

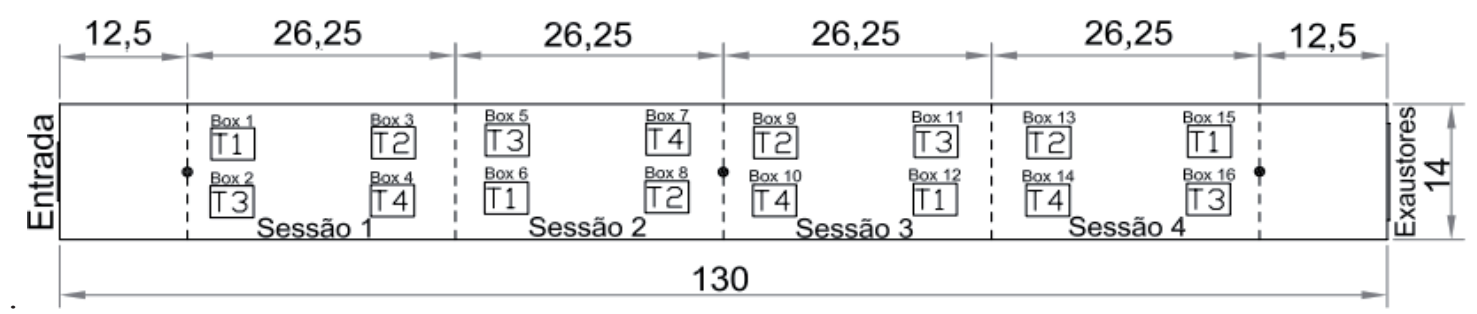

Legenda: • Datalogger; $\square$ boxes de contenção; : Divisória entre blocos; $\rightarrow$ cotas em metros

Fonte: Elaboração dos autores.

Quando se analisa a CA em função das sessões entre os galpões, nota-se que a mesma apresentouse melhor $(\mathrm{P}<0,05)$ apenas na sessão 1 no galpão 2 , enquanto que nas demais sessões, ela foi maior para o galpão 1 .

Os melhores resultados de CA entre as sessões do SRAE+SETV deve-se, provavelmente, ao ambiente mais favorável e homogêneo proporcionado por este sistema. Estes resultados corroboram com os encontrados por Oliveira et al. (2006) que avaliando o efeito da temperatura ambiente sobre o desempenho e as características de carcaça de frangos de corte dos 22 aos 42 dias de idade obtiveram melhora gradativa na $\mathrm{CA}$ observada entre 16 e $25^{\circ} \mathrm{C}$, confirmando a influência destas temperaturas na eficiência da utilização de energia para o ganho de peso das aves nesta faixa de idade. 
Embora as condições de temperatura no SRAE e SARAE+SETV tenha se apresentado acima das estabelecidas como ótima, nenhuma diferença foi encontrada para as medidas de desempenho quando relacionadas aos níveis de energia utilizados nas rações experimentais, efeito observado apenas entre os galpões estudados. Portanto, os níveis de energia nas rações não influenciaram diretamente as variáveis analisadas, com exceção do peso da gordura abdominal conforme mostrado na Figura 3.

Figura 3. Efeito dos níveis de energia metabolizável (EM) no peso da gordura abdominal.

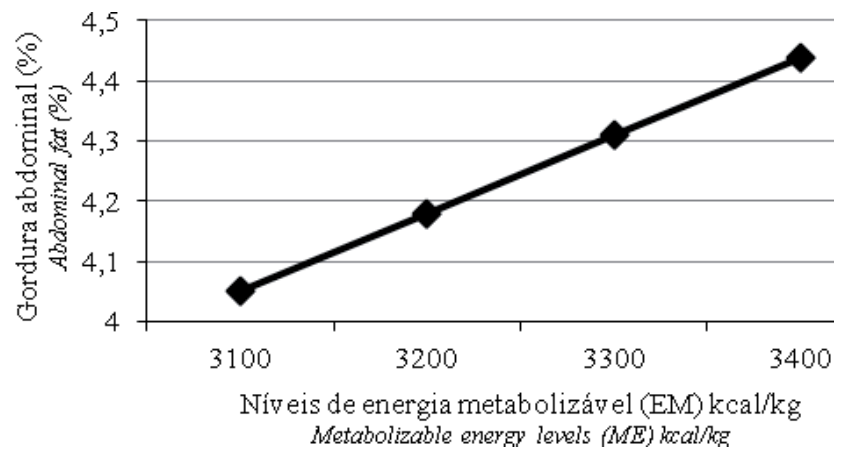

Fonte: Elaboração dos autores.

A deposição de gordura abdominal aumentou de forma linear com o aumento nos valores de energia na ração. Este resultado corrobora com os encontrados por Macari e Furlan (1994) que, avaliando os efeitos dos níveis de EM em rações (2900 a $3450 \mathrm{kcal} / \mathrm{kg}$ ), também constataram aumento linear no teor de gordura da carcaça de frangos de corte, em razão de níveis mais altos de energia contidos na ração.

Na Tabela 6 estão expressas as médias estimadas do peso da ave viva (PAV), peso da ave eviscerada (PAE), peso do coração (PC) e peso do fígado (PF) em função do galpão e dos níveis de energia na ração. Nota-se que as variáveis PAV e PAE, apresentaram maiores valores no galpão com SRAE+SETV em relação ao galpão com SRAE, resultados que podem estar relacionados com as melhores condições ambientais encontradas neste primeiro sistema, fazendo com que a energia consumida por parte desses animais fosse direcionada ao crescimento e ganhos de peso dos mesmos.

O peso do fígado (PF) tem redução no estresse por calor, provavelmente devido à redução na atividade desse órgão (PLAVNIK; YAHAV, 1998). No frio o aumento do peso relativo dos órgãos está associado à necessidade de maior produção de calor corporal. A redução do tamanho destes órgãos, em ambiente de alta temperatura, corresponde a tentativa da ave reduzir a produção de calor interno (OLIVEIRA et al., 2006). Por este motivo, a maior massa absoluta para fígado obtida no sistema SRAE+SETV, se deve provavelmente, às condições de temperaturas mais amenas proporcionadas pelo sistema evaporativo de tijolos vazados associado aos nebulizadores. 
Tabela 6. Médias estimadas de peso da ave viva (PAV) (kg), peso da ave eviscerada (PAE) (kg), peso do coração (PC) (\%) e peso do fígado (PF) (\%), em função do galpão e dos níveis de EM (kcal/kg).

\begin{tabular}{|c|c|c|c|c|c|c|}
\hline \multicolumn{7}{|c|}{ Níveis de EM (kcal/kg) } \\
\hline Variável & Galpão & 3100 & 3200 & 3300 & 3400 & Média \\
\hline PAV & $\begin{array}{c}\text { SRAE } \\
\text { SRAE+ } \\
\text { SETV }\end{array}$ & $\begin{array}{l}2,52 \pm 0,11 \\
2,74 \pm 0,08\end{array}$ & $\begin{array}{l}2,70 \pm 0,08 \\
2,74 \pm 0,17\end{array}$ & $\begin{array}{l}2,69 \pm 0,11 \\
2,90 \pm 0,08\end{array}$ & $\begin{array}{l}2,67 \pm 0,17 \\
2,82 \pm 0,08\end{array}$ & $\begin{array}{l}2,64 \pm 0,13 \mathrm{~A} \\
2,80 \pm 0,12 \mathrm{~B}\end{array}$ \\
\hline PAE & $\begin{array}{c}\text { SRAE } \\
\text { SRAE+ } \\
\text { SETV }\end{array}$ & $\begin{array}{l}1,72 \pm 0,07 \\
1,94 \pm 0,07\end{array}$ & $\begin{array}{l}1,91 \pm 0,06 \\
1,94 \pm 0,16\end{array}$ & $\begin{array}{l}1,89 \pm 0,10 \\
2,03 \pm 0,07\end{array}$ & $\begin{array}{l}1,87 \pm 0,14 \\
1,96 \pm 0,05\end{array}$ & $\begin{array}{l}1,85+0,11 \mathrm{~B} \\
1,97+0,09 \mathrm{~A}\end{array}$ \\
\hline $\mathrm{PC}$ & $\begin{array}{c}\text { SRAE } \\
\text { SRAE+ } \\
\text { SETV }\end{array}$ & $\begin{array}{l}0,76 \pm 0,17 \\
0,73 \pm 0,10\end{array}$ & $\begin{array}{l}0,63 \pm 0,04 \\
0,71 \pm 0,07\end{array}$ & $\begin{array}{l}0,66 \pm 0,04 \\
0,68 \pm 0,04\end{array}$ & $\begin{array}{l}0,69 \pm 0,08 \\
0,68 \pm 0,03\end{array}$ & $\begin{array}{l}0,69 \pm 0,10 \mathrm{~A} \\
0,70 \pm 0,07 \mathrm{~A}\end{array}$ \\
\hline $\mathrm{PF}$ & $\begin{array}{l}\text { SRAE } \\
\text { SRAE+ } \\
\text { SETV }\end{array}$ & $\begin{array}{l}3,16 \pm 0,59 \\
2,91 \pm 0,22\end{array}$ & $\begin{array}{l}2,92 \pm 0,12 \\
2,87 \pm 0,26\end{array}$ & $\begin{array}{l}2,83 \pm 0,30 \\
2,79 \pm 0,11\end{array}$ & $\begin{array}{l}2,76 \pm 0,31 \\
3,05 \pm 0,28\end{array}$ & $\begin{array}{l}2,92 \pm 0,37 \mathrm{~A} \\
2,91 \pm 0,23 \mathrm{~A}\end{array}$ \\
\hline
\end{tabular}

Médias seguidas de letras diferentes diferem entre si pelo teste de $\mathrm{F}$ a $5 \%$.

Fonte: Elaboração dos autores.

\section{Conclusões}

A utilização do sistema de resfriamento adiabático evaporativo (SRAE) foi mais eficiente quando associado ao sistema evaporativo de tijolos vazados (SETV).

O SRAE+SETV proporcionou um ambiente mais confortável e homogêneo mostrando efeito para os parâmetros produtivos e favorecendo a conversão alimentar (CA).

Os níveis de energia não influenciaram as variáveis analisadas, com exceção da deposição da gordura abdominal.

\section{Referências}

BAÊTA, F. C.: SOUZA, C. F. Ambiência em edificações rurais: conforto animal. Viçosa: UFV, 1997. 246 p.

BAZIZ, H. A.; GERAERT, P. A.; GUILLAUMIN, S. Chronic heat exposure enhances fat deposition and modifies muscle and fat partition in broiler carcasses. $J$. Poultry Science, Honduras, v. 75, n. 4, p. 505-513, 1996.
BELLAY, T.; TEETER, R. G. Broiler water balance and thermobalance during thermoneutral and high ambient temperature exposure. J. Poultry Science, Honduras, v. 72, n. 2, p. 116-124, 1993.

CAVIGLIONE, J. H.; KIIHL, L. R. B.; CARAMORI, P. H.; OlIVEIRA, D. Cartas climáticas do Paraná. Londrina : IAPAR, 2000. CD-ROM.

DALE, N. M.; FULLER, H. L. Effect of diet composition on feed intake end growth of chicks under heat stress. II Constant x cycling temperatures. J. Poultry Science, Honduras, v. 59, n. 9, p. 1431-1441, 1980.

GERAERT, P. A.; PADILHA, J. C. F.; GUILLAUMIN, $\mathrm{S}$. Metabolic and endocrine changes induced by chronic heat exposure chickens: biological and endocrinological variables. British Journal of Nutrition, London, v. 75, n. 2, p. 205-216, 1996.

LANA, G. R. Q.; ROSTAGANO, H. S.; ALBINO, L. F. T.; LANA, A. M. Q. Efeito da temperatura ambiente e da restrição alimentar sobre o desempenho e composição de carcaça de frangos de corte. Revista Brasileira de Zootecnia, Viçosa, MG, v. 29, n. 4, p. 1117-1123, 2000.

MACARI, M.; FURLAN, R. L. Fisiologia aviária aplicada a frangos de corte. Jaboticabal: FUNEP/ UNESP, 1994. 296 p. 
MEDEIROS, C. M.; BAÊTA, F. C.; OLIVEIRA, R. F. M.; TINÔCO, I. F. F.; ALBINO, L. F. T.; CECON, P. R. Índice térmico ambiental de produtividade para frangos de corte. Revista Brasileira de Engenharia Agrícola e Ambiental, Campina Grande, v. 9, n. 4, p. 660-665, 2005.

MOURA, D. J. Ambiência na avicultura de corte. In: SILVA, I. J. O. Ambiência na produção de aves em clima tropical. Jaboticabal. SBEA, p. 75-149, 2001.

NEIVA, J. N. M.; TEIXEIRA, M.; TURCO, H. N.; OLIVEIRA, S. M. P.; MOURA, A. A. A. N. Efeito do estresse climático sobre os parâmetros produtivos e fisiológicos de ovinos Santa Inês mantidos em confinamento na região litorânea do Nordeste do Brasil. Revista Brasileira de Zootecnia, Viçosa, MG, v. 33, n. 3, p. 668-678, 2004.

OLIVEIRA, G. A.; OLIVEIRA, R. F. M.; DONZELE, J. L.; CECON, P. R.; VAZ, R. G. M. V.; ORLANDO, U. A. D. Efeito da temperatura ambiente sobre o desempenho e as características de carcaça de frangos de corte dos 22 aos 42 dias. Revista Brasileira de Zootecnia, Viçosa, MG, v. 35, n. 4, p. 1398-1405, 2006.

PLAVNIK, I.; YAHAV, S. Effect of environmental temperature on broiler chickens subjected to growth restriction at na early age. J. Poultry Science, Honduras, v. 77 , n. 6 , p. $870-872,1998$.
RODRIGUES, E. H. V. Desenvolvimento e avaliação de um sistema de resfriamento evaporativo por aspersão intermitente, na cobertura de aviários usando modelos de escala distorcida. 1998. Tese (Doutorado em Engenharia Agrícola) - Universidade Estadual de Campinas, Campinas.

ROSTAGNO, H. S.; ALBINO, L. A. T.; DONZELLE, J. L.; GOMES, P. C.; OLIVEIRA, R. F.; LOPES, D. C.; FERREIRA, A. S.; BARRETO, S. L. T. Tabelas brasileiras para aves e suinos: composição de alimentos e exigências nutricionais. 2. ed. Viçosa: UFV, 2005. 186 p.

STATISTICAL ANALYSIS SYSTEM INSTITUTE SAS. Sas statistic guide for personal computers. Cary, North Carolina: SAS Institute Inc., 2008.

TINÔCO, I. F. F. Avicultura industrial: novos conceitos de materiais, concepções e técnicas construtivas disponíveis para galpões avícolas brasileiros. Revista Brasileira de Ciência Avícola, Campinas, v. 3, n. 1, p. 1-26, 2001.

WELKER, J. S.; ROSA, A. P.; MOURA, D. J.; MACHADO, L. P.; CATELAN, F.; UTTPATEL, R. Temperatura corporal de frangos de corte em diferentes sistemas de climatização. Revista Brasileira de Zootecnia, Viçosa, MG, v. 37, n. 8, p. 1463-1467, 2008. 